\title{
Effect of Functionalized Carbon Nanotubes and their Citric Acid Polymerization on Mesenchymal Stem Cells In Vitro
}

\author{
Rosa L. Garnica-Gutiérrez, ${ }^{1,2}$ Luis A. Lara-Martínez, ${ }^{3}$ Eduardo Palacios, ${ }^{4}$ Felipe Masso (D), \\ Alejandra Contreras, ${ }^{6}$ Salomón Hernández-Gutiérrez, ${ }^{3}$ and Felipe Cervantes-Sodi ${ }^{1}{ }^{1}$ \\ ${ }^{1}$ Departamento de Física y Matemáticas, Universidad Iberoamericana, Prolongación Paseo de la Reforma 880, 01219 Lomas de Santa \\ Fe, MEX, Mexico \\ ${ }^{2}$ Facultad de Ingeniería, Universidad Panamericana, Augusto Rodin 498, Benito Juárez, 03920 Insurgentes Mixcoac, MEX, Mexico \\ ${ }^{3}$ Molecular Biology Laboratory, School of Medicine, Universidad Panamericana, Augusto Rodin 498, Benito Juárez, 03920 \\ Insurgentes Mixcoac, MEX, Mexico \\ ${ }^{4}$ Laboratorio de Microscopía Electrónica de Ultra Alta Resolución, Instituto Mexicano del Petróleo, Eje Central Lázaro Cárdenas \\ Norte 152, 07730 San Bartolo Atepehuacán, MEX, Mexico \\ ${ }^{5}$ Instituto Nacional de Cardiología, Ignacio Chávez, Juan Badiano, Sección XVI, 14080, Mexico \\ ${ }^{6}$ Laboratorio de Investigación en Biología del Desarrollo y Teratogénesis Experimental, Hospital Infantil, Dr. Márquez 162, \\ 06720, Mexico
}

Correspondence should be addressed to Felipe Cervantes-Sodi; felipe.cervantes@ibero.mx

Received 27 November 2017; Revised 10 May 2018; Accepted 17 May 2018; Published 9 July 2018

Academic Editor: Chengyuan Wang

Copyright (c) 2018 Rosa L. Garnica-Gutiérrez et al. This is an open access article distributed under the Creative Commons Attribution License, which permits unrestricted use, distribution, and reproduction in any medium, provided the original work is properly cited.

\begin{abstract}
The effects of acid-functionalized and polycitric acid- (PCA-) polymerized carbon nanotubes (CNTs) in contact with the extracellular membrane of mesenchymal stem cells (MSC), a genetically unmodified cell line with differentiation capability, was evaluated with different cellular parameters. The modified CNTs show differences in the analyzed biological behaviors, that is, intracellular incorporation, cell proliferation, apoptosis, and cytotoxicity as compared with those unpolymerized nanotubes. Due to the reduced cellular uptake of polymerized CNTs, PCA-polymerized CNTs are less cytotoxic and are associated with less apoptotic cell death than the acid-functionalized ones. The effects of nitrogen-doped CNTs (CNx) is also reported, showing that functionalized undoped CNTs present strong stimulation of cell proliferation, whereas functionalized and polymerized CNxs stimulate an apoptotic behavior. The study of MSCs in contact with CNTs and PCA is challenging due to the complexity of its various signaling components. Our results provide basis for further studies aimed to understand the relevant role that the interaction of these nanotubes with extracellular membrane could have a crucial structure for tissue grafting.
\end{abstract}

\section{Introduction}

Carbon nanotubes (CNTs) show great promise and notable breakthroughs have been done due to their optical [1], electrical [2], and mechanical properties, which have direct applications in biological areas [3] such as trackers for detection in cellular micro environment [4], as vehicles for delivery agents $[4-6]$, or in cell differentiation $[7,8]$ and tissue regeneration $[8,9]$.
To obtain biocompatible features from CNTs, and because of their hydrophobic behavior, CNTs are commonly subject to different functionalization processes. The most common of these involves an acid treatment, generating carboxylic groups at the walls of the CNTs, producing functionalized CNTs (fCNT) [10-14]. However, this treatment has been found as the cause of cytotoxic effects in specific cell lines [13-15]. Another way to generate functional groups on CNTs is by modification with dendritic and hyperbranched 
biocompatible polymers [16-18] by attaching chains, like molecules of the extracellular matrix, to the CNTs walls [18], allowing biocompatibility and an easier interaction between the polymerized CNTs and the cells. In addition, some polymers also improve the solubility in water and the dispersion in biological fluids $[15,19]$.

For example, polyethylene terephthalate (PET) and polyurethane (PU) have shown a favorable cellular response in MSCs $[19,20]$. Synthetic polyethylene glycol (PEG) together with chondroitin sulfate (CS) has been used as scaffolding on chondrogenesis induced by MCSs [21-23]. Nevertheless, some results of the toxicity of polymerized CNTs with PET, PU, and PEG $[20,21,24]$ suggest that these polymerizations cause toxic effects on MSCs, leading to the ongoing search for different, noncytotoxic polymers [25].

Polycitric acid (PCA) [16, 17, 26-30], a hyperbranched polymer with a highly biocompatible surface [16], has been proposed for building biological scaffolding and increasing the hydrophilicity of CNTs $[17,28]$, reducing their aggregation and size polydispersity, and consequently diminishing their cytotoxicity $[16,29,31]$. Additionally, it has been found that PCA polymerization process does not generate pollutant particles [27].

The polymerization of MWNTs with PCA starts with the acid-functionalized MWNTs (fMWNT) and is followed by the addition of PCA, which covalently joins carboxylic functional groups of PCA and fMWNTs via a cleavable ester, obtaining polycitric acid-MWNTs (PMWNTs), an interesting material for nanomedicine applications [17, 27, 28, 30, 32]. Although in cell therapy, mesenchymal stem cells (MSCs) cultured on scaffolding are a real option in the field of tissue engineering [33] for generate or repair of new tissue $[8,9,34,35]$, one of the major limitations is still the lack of anchoring between the damaged tissue and the cells that are supplied, because the MSCs applied by suspension directly in damaged areas produce little or null improvements on the surrounding damaged tissue [36] by transdifferentiation effect. Thus, the production of adequate scaffolds for proliferation and anchorage of MSCs is a fundamental aspect for future investigation [37] Despite that polymerized CNTs with other materials have effects on the MSC behavior, promoting adhesion $[18,38-40]$, changing stem cell's shape $[7,8,41,42]$, and providing signals that may promote proliferation or differentiation [18], it is unknown if polymerized CNTs with PCA could help as intermediaries or structurally could act as a kind of staple between the extracellular matrix of a damaged tissue with the extracellular matrix of MSCs previously treated in vitro with PMWNT before injected. However, based on the reports of cytotoxic effects of fCNTs $[11,14,15,19,25]$ and polymerized CNTs (PCNT), with PEG, PU, and PET [19, 25], prior to considering PMWCNT as biological scaffolding for MSCs, it is mandatory and fundamental to start by performing cytotoxic assays of cells in contact with fCNTs and fPCA-CNTs. Thus, the aim of this work is to generate and characterize a set of functionalized and PCA-polymerized CNTs to evaluate their behavior on a cellular in vitro model of MSCs derived from primary cultures (bone marrow). This model ensures a clean and clear genetic background without the presence of genetic disorders such as those accumulated in cell lines previously preestablished and characterized, like those of traditional cell lines [43]. Therefore, MSCs are an excellent model to evaluate several biological parameters such as proliferation, apoptosis, cytotoxicity [36] changes in their multipotent differentiation patterns $[38,41,42]$, and cell proliferation [18]. The, CNTs used in this work were fully characterized after functionalization and PCA polymerization. Then, cell viability and apoptosis assays were performed, and by confocal microscopy the cell morphology and presence of CNTs were evaluated.

\section{Materials and Methods}

2.1. Synthesis of CNTs. MWNTs and nitrogen-doped nanotubes $(\mathrm{CNx})$ were synthesized by chemical vapor deposition (CVD), following a procedure similar to the one reported by Botello-Méndez et al. [44]. Mainly a tubular furnace with a tubular quartz reactor, and quartz substrates (Figure 1(a)), is heated under a $0.21 / \mathrm{min}$ Ar flow. After reaching $850^{\circ} \mathrm{C}$, microdroplets of ferrocene/toluene (3.5/96.5 wt\%) or ferrocene/benzylamine (3.5/96.5 wt\%) solutions were supplied-as the Fe, $\mathrm{C}$, and $\mathrm{N}$ feedstock-by a spray pulverization chamber (Pyrosol 7901, France), at a flow rate of $2.5 \mathrm{l} / \mathrm{min}$. After 15 minutes of CVD reaction, the system is allowed to cool down to room temperature. MWNTs and CNx were obtained from the ferrocene/ toluene and ferrocene/benzylamine solutions, respectively. The length of the nanotubes are around $400 \mu \mathrm{m}$, growing in a "forest-like" form perpendicular to the quartz substrate surfaces (Figure 1(a)).

2.2. Functionalization. After the CNT synthesis, both types of nanotubes, MWNTs and $\mathrm{CNx}$, were independently acid treated for functionalization (Figure 1(b)) [45]. $0.6 \mathrm{~g}$ of the CNTs were sonicated (at $750 \mathrm{~W}$ and $20 \mathrm{kHz} / \mathrm{kwatts}$ ) for 4 hours [46] in $100 \mathrm{ml}$ of an $\mathrm{H}_{2} \mathrm{SO}_{4} / \mathrm{HNO}_{3} 3: 1$ by $3 \mathrm{M}$ acid solution [13]. The solution was filtered and washed with $\mathrm{NaOH} 3 \mathrm{M}$ and bidistilled water. Finally, solutions of fMWNTs and functionalized $\mathrm{CNx}(\mathrm{fCNx})$ in bidistilled water were prepared at 3 different concentrations, $1000 \mathrm{ng} / \mathrm{ml}, 100 \mathrm{ng} / \mathrm{ml}$, and $10 \mathrm{ng} / \mathrm{ml}$, by ultrasonic processing for 4 hours [46].

\subsection{Citric Acid Polymerization onto FMWNTs and FCNxs.} A total of $0.1 \mathrm{~g}$ of the respective functionalized CNTs, either fMWNTs or fCNxs, was added to a round bottom flask (Figure 1(c)); simulating the polymerization ampule equipment, the flask was set on a water bath, with magnetic stirrer and a low vacuum inlet. Five grams of monohydrate citric acid was added to the flask. The mixture was heated up to $120^{\circ} \mathrm{C}$ and stirred at this temperature for $30 \mathrm{~min}$. After removing the water with a vacuum line, the reaction temperature was raised to $140^{\circ} \mathrm{C}$ and stirred at this temperature for $1 \mathrm{~h}$. Again, the produced water was removed by the vacuum line, and the reaction temperature was raised to $160^{\circ} \mathrm{C}$ [28]. Hence, citric acid could be polymerized onto the fMWNTs or fCNxs through polycondensation reaction. Polymerization was continued in 


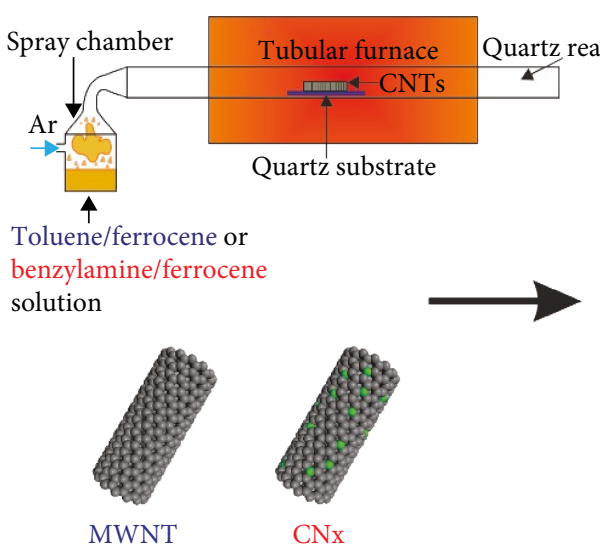

(a)

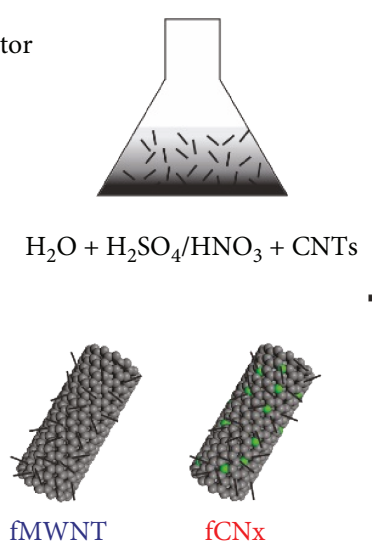

(b)

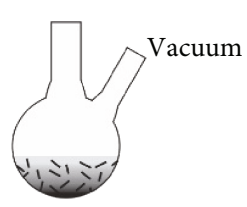

$\mathrm{fCNTs}+\mathrm{PCA} \longrightarrow \mathrm{PCNTs}$

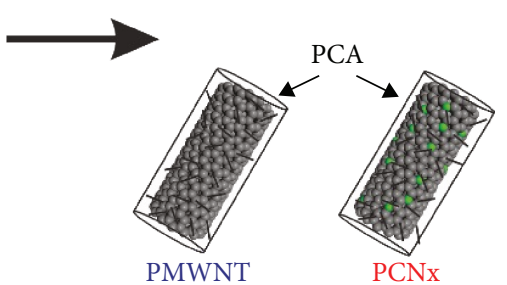

(c)

FIGURE 1: Schematic representation of the three steps for the nanotube synthesis (a), acid functionalization (b), and PCA polymerization (c), as described in the methodology. The bottom panels represent a pristine MWNT and a pristine CNx, with green spheres representing the nitrogen dopants. Nanotubes are functionalized, which causes some alteration in their external layer and finally polymerized, covered by a PCA layer.

this temperature under dynamic vacuum for $1.5 \mathrm{~h}$. The procedure was like the one reported Sarlak et al. [26]. Due to the poor solubility of fCNTs and citric acid in the organic solvents, melting esterification is the best method for a polycondensation reaction between fCNTs and citric acid $[27,28]$. We used monohydrate citric acid to overcome the problem of the decomposition of citric acid problem because its melting point is $100^{\circ} \mathrm{C}$. At this temperature, polycondensation reaction partially occurs between PCA and fMWNTs or fCNxs. Then, water can be removed, and an increment of the reaction temperature leads to hyperbranched polycitric acid grafted onto fCNTs or fCNxs, obtaining PCAylated MWNTs (PMWNT) and PCAylated $\mathrm{CNx}(\mathrm{PCNx})$, respectively (Figure 1(c)). The mixture was cooled and dissolved in acetone, and the product was precipitated in bidistilled water. Finally, for the biological tests, as for fMWNTs and fCNXs, solutions of PMWNTs and PCNxs were prepared at $1000 \mathrm{ng} / \mathrm{ml}$, $100 \mathrm{ng} / \mathrm{ml}$, and $10 \mathrm{ng} / \mathrm{ml}$ using bidistilled water in an ultrasonic processor for 4 hours.

2.4. CNT Characterization. For morphological characterization, a dual-beam scanning electron microscope (SEM, Nova 200 Nanolab, USA) was used, coupled with an X-ray Si (Li) ultrathin window energy dispersive spectrometer (EDS) for low atomic number detection. The quantitative estimation of the elemental atomic percent was done with the ZAF method implemented on the EDAX EDS Genesis software, with a maximum accuracy error of $1 \mathrm{wt} . \%$. A transmission electron microscope (TEM, Tecnai G2 F30 S-TWIN, UK) was used to analyze the CNT structure. Statistical evaluation of diameters was carried out on samples containing fMWNTs, fCNx, PMWNTs, and PCNxs. The Raman analysis (Horiba Jobin Yvon, LabRAM HR800, France) was performed with a $633 \mathrm{~nm}$ laser. The infrared (IR) spectra were examined with a Fourier-transform IR spectrometer (Thermo Scientific, Nicolet iS5 ID5 ATR, USA) from 1000 to $3500 \mathrm{~cm}^{-1}$. Thermogravimetric analysis (TGA) (Q500,
USA) were performed under a $\mathrm{N}_{2}$ flow of $50 \mathrm{ml} \cdot \mathrm{min}^{-1}$ following a calibration procedure of an isothermal heating in a heating rate of $2^{\circ} \mathrm{C} / \mathrm{min}$ reaching $100^{\circ} \mathrm{C}$ for $30 \mathrm{~min}$. Then, thermal analysis started at room temperature reaching $200^{\circ} \mathrm{C}$ with a heating rate of $2^{\circ} \mathrm{C} / \mathrm{min}$.

2.5. Cell Culture. MSCs derived from rat bone marrow were isolated and cloned from a heterogeneous culture [47], seeded at $10000 \mathrm{cell} / \mathrm{ml}$ suspensions, and grown in $3.0 \mathrm{~cm}^{2}$ plate dishes with $\alpha$-MEM medium (Sigma-Aldrich, USA) with supplemented fetal bovine serum (10\%), penicillin $(10,000 \mathrm{U})$, streptomycin $(10 \mathrm{mg} / \mathrm{ml})$, and amphotericin $\mathrm{B}$ $(25 \mathrm{mg} / \mathrm{ml})$ (Sigma-Aldrich, USA). Then, the culture was incubated at $37^{\circ} \mathrm{C}$ and $5 \% \mathrm{CO}_{2}$ with the three different concentrations of each kind of nanotubes: fMWNTs, PMWNTs, fCNxs, and PCNxs, at 10, 100, and $1000 \mathrm{ng} / \mathrm{ml}$.

2.6. Cellular Proliferation. Following the cell culture preparation, a trypan blue exclusion test (TBET) [14] was performed at $0,24,48,72$, and 144 hours. The cells were trypsinized and resuspended in fresh culture medium. Finally, cells were counted on a hemocytometer. The cellular proliferation test was done in triplicate.

2.7. Apoptosis Assay. The cells treated at different concentrations $(10,100$, and $1000 \mathrm{ng} / \mathrm{ml})$ of fMWNTs, PMWNTs, fCNxs, PCNxs, and MSCs during 48, 72, and 144 hours were trypsinized and resuspended using an Annexin V/propidium iodide assay kit (ellEvent, USA). The cells were washed with phosphate-buffered saline/bovine sserum albumin (PBS/BSA) and incubated at room temperature with a solution of annexin-V-FLUOS and propidium iodide for $30 \mathrm{~min}$, as suggested by Jiang et al. [47]. The cells were then analyzed by flow cytometry, monitoring the fluorescence emission at $395 / 525 \mathrm{~nm}$ for annexin V-FITC and $483 / 659 \mathrm{~nm}$ for PI in a flow cytometer (FACSCalibur; Becton Dickinson, USA). The cells were seeded by triplicate; the assay was carried on in untreated MSCs as pure control 


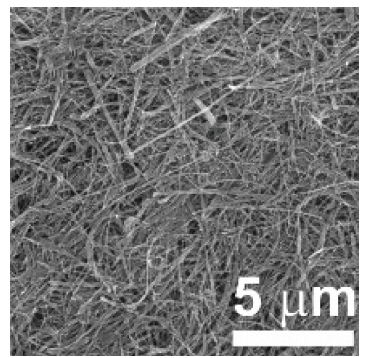

(a)

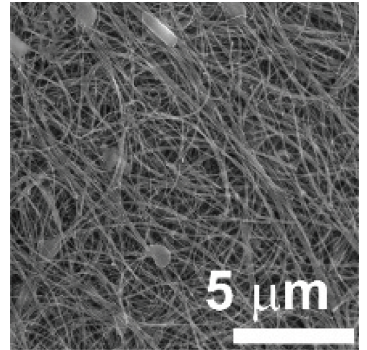

(e)

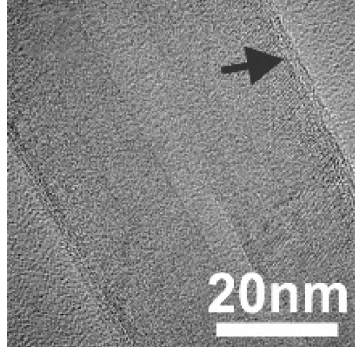

(b)

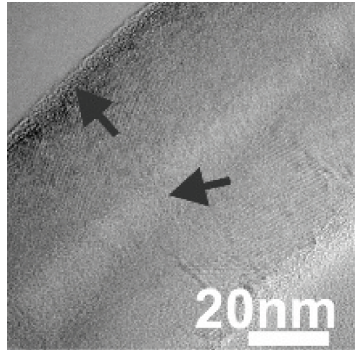

(f)

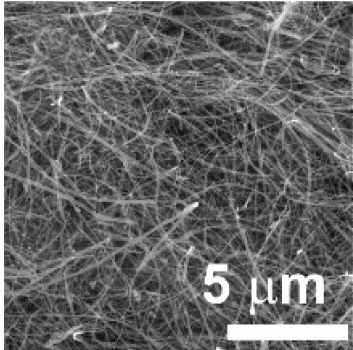

(c)

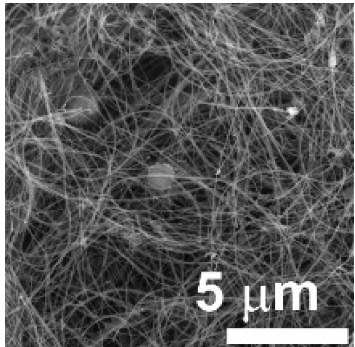

(g)

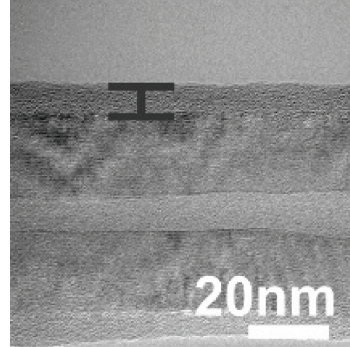

(d)

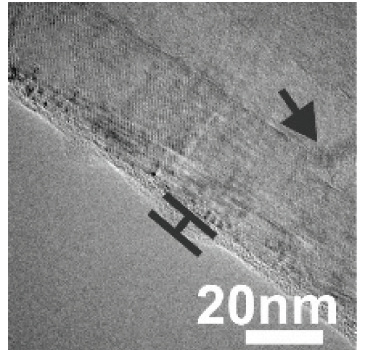

(h)

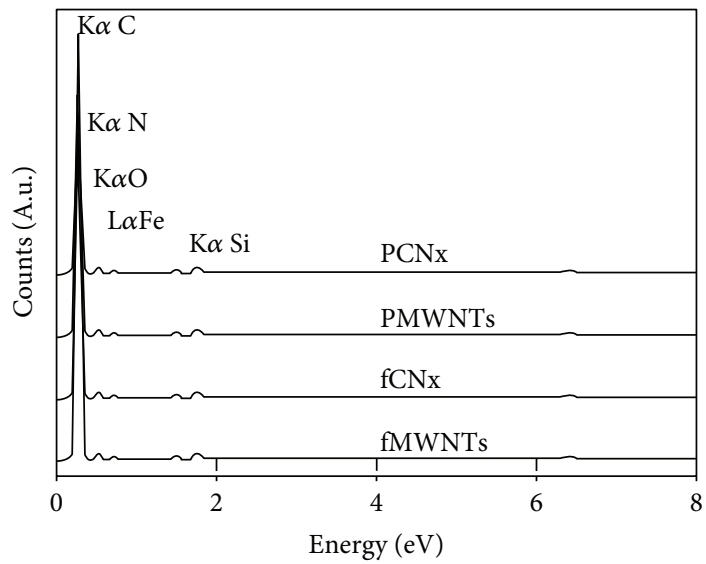

(i)

Figure 2: Representative SEM micrographs of (a, b) fMWNT, (c, d) PMWNT, (e, f) fCNxs, and (g, h) PCNxs. Black arrows in (b) show the functionalized edge of the CNT, while the arrows in $(\mathrm{f}, \mathrm{h})$ indicate the typical bamboo-like structure of the CNx. Arrows also indicate the thin PCA film on the surface of the (d) MWNT and the (h) CNx. The EDS spectra of the four samples are included (i); the quantitative data for C, $\mathrm{Fe}, \mathrm{N}$, and $\mathrm{O}$ is provided in Table 1, with a faint silicon signal arising from the substrate.

and MSC positive control containing 25, 12.5, and $2.5 \mu \mathrm{l}$ of hydrogen peroxide, respectively.

2.8. Confocal. Cells were grown on cover slips, treated at $100 \mathrm{ng} / \mathrm{ml}$ of each type of nanotubes after 72 hours of incubation time, which was washed with PBS and fixed with $4 \% \mathrm{w} / \mathrm{v}$ paraformaldehyde (PFA) (Sigma-Aldrich, USA). A nuclear immunofluorescence staining was performed with Draq7 (bio status). The presence of nanotubes was revealed by autofluorescence using a laser beam at 488 and an emission filter 505-30 LB, while nuclei were seen also at 488 and 633 LB. Images were captured using a confocal microscopy (Zeiss, Germany) and analyzed by the Zen 2009 software and a confocal microscope Leica Mod. TCS sp $8 x$ with a LAS AF 3.3.0 software.
2.9. Statistics. Three independent repetitions of each biological experimental treatment were done. Data are expressed as a mean standard deviation of the experiments. Statistic analysis was performed by analysis of variance (ANOVA). Statistical significance was inferred at $p 0.05$.

\section{Results}

3.1. Nanotubes Characterization. The morphology and structure of fMWNTs, PMWNTs, fCNxs, and PCNxs are shown in the micrographs of Figure 2. The average width of the nanotubes after the functionalization is shown in Table 1, suggesting that PCA increases their diameter by $20 \%$ for fMWNTs and $24 \%$ for fCNxs. The TEM micrographs in Figures 2(b) and 2(f) show some degree of disorder on the 
TABLE 1: Data of the four types of nanotubes including C, N, and Fe wt.\% estimated by EDS with an estimated error of $1 \%$; diameter of the CNTs obtained by SEM and the $\mathrm{I}_{\mathrm{D}} / \mathrm{I}_{\mathrm{G}}$ ratio by Raman spectroscopy.

\begin{tabular}{|c|c|c|c|c|c|c|}
\hline & (wt\% C) & $(\mathrm{wt} \% \mathrm{O})$ & $(\mathrm{wt} \% \mathrm{~N})$ & $(\mathrm{wt} \% \mathrm{Fe})$ & Diameter $(\mathrm{nm})$ & $\mathrm{I}_{\mathrm{D}} / \mathrm{I}_{\mathrm{G}}$ \\
\hline fMWNTs & 94.98 & 2.6 & - & 2.44 & $\approx 89.2$ & 0.41 \\
\hline PMWNTs & 93.96 & 4.23 & - & 1.81 & $\approx 107.2$ & 0.43 \\
\hline $\mathrm{fCNx}$ & 92.48 & 3.3 & 2.84 & 1.38 & $\approx 69.3$ & 0.89 \\
\hline PCNx & 93.22 & 3.82 & 1.01 & 1.94 & $\approx 86.4$ & 0.82 \\
\hline METHOD & EDS-SEM & EDS-SEM & EDS-SEM & EDS-SEM & SEM & RAMAN \\
\hline
\end{tabular}

external walls of the acid-treated CNTs, which complementing with the IR spectroscopy information (Figure 3) indicates the presence of carboxyl functional groups on the walls of the nanotubes, generated during the acid functionalization $[45,46]$. A different kind of disorder is also noticeable as bamboo-like structures in the inner part of the fCNxs and PCNxs as shown in Figures 2(f) and 2(h), indicating the presence of nitrogen as a doping agent [48]. During synthesis of CNxs, the nitrogen tends to incorporate pentagons on the hexagonal structure of the nanotube, affecting its crystallinity and inducing curvature on the inner nanotube surfaces, generating the bamboo-shaped structures in the interior $[49,50]$. Currently, CNxs are being investigated, since the effects of these irregularities may favor the interaction with polymers [48]. The polymerization of the CNTs by PCA is noticeable in Figures 2(d) and $2(\mathrm{~h})$, where a thin layer of polymer covers the corresponding nanotubes, like those reported by Jiang et al. [47].

The elemental compositions for each of the four types of CNTs are shown in the EDS spectra (bottom of Figure 2 and Table 1), confirming that the nanotubes do not contain enough weight percentage of Fe pollutants that may cause cytotoxicity $[15,48]$. The Fe nanoparticles are found inside the CNTs, and thus not in contact with the environment and finally not with the MSCs, avoiding chance of cytotoxicity by Fe. In fact, one of the positive side effects of the functionalization is to remove most of the catalyst nanoparticles or other compounds that are in contact with the nanotube during growth [16]. Raman spectra in Figure 4(a)) yield data about the types of nanotubes and their defects [51]. Impurities and defects of carbon nanotubes are usually understood on the basis of the $\mathrm{D}$ band at about $1350 \mathrm{~cm}^{-1}$, as reported by Datsyuk et al. [52] where the intensity (I) of the D band is related to the concentration number of defects. In contrast, the $G$ band is associated with the graphitic or crystalline structure of the tubes and is located at $1588 \mathrm{~cm}^{-1}$. The $\mathrm{I}_{D} / \mathrm{I}_{G}$ ratio has been obtained for the four types of nanotubes, and it relates the defects and the crystallinity of the tubes. Functionalization and polymerization increase the amount of disordered carbon caused by the partial alteration of fMWNTs and fCNxs during the exfoliation of bundles and the polymerization treatment $[50,53]$. The intensity of the D and $\mathrm{G}$ bands is almost constant for the MWNTs and the $\mathrm{CNx}$, respectively (Figure 4); that is, only a small change in the $\mathrm{I}_{D} / \mathrm{I}_{G}$ ratio appears when functionalized nanotubes are polymerized. As expected, fMWNTs and PMWNts show a higher intensity in $G$ band in comparison with fCNxs

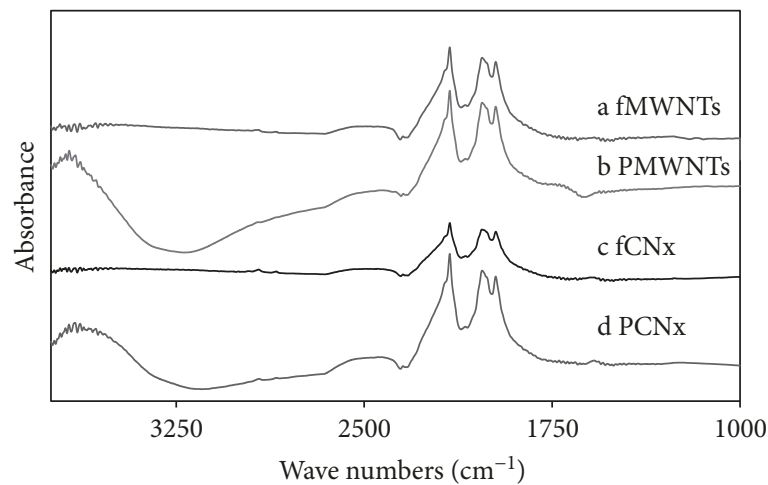

FIgURE 3: Infrared spectra of $(a, c)$ acid-functionalized MWNTs and CNxs, respectively, showing the bands between 1750 and $2200 \mathrm{~cm}^{-1}$ related to the $\mathrm{C}-\mathrm{C}$ bonds. The $\mathrm{OH}$ band obtained by functionalization is present at $2500 \mathrm{~cm}^{-1}$. For the polymerized CNTs (b, d), the broad band at $3600 \mathrm{~cm}^{-1}$ is related to the $\mathrm{OH}$ groups associated to PCA.

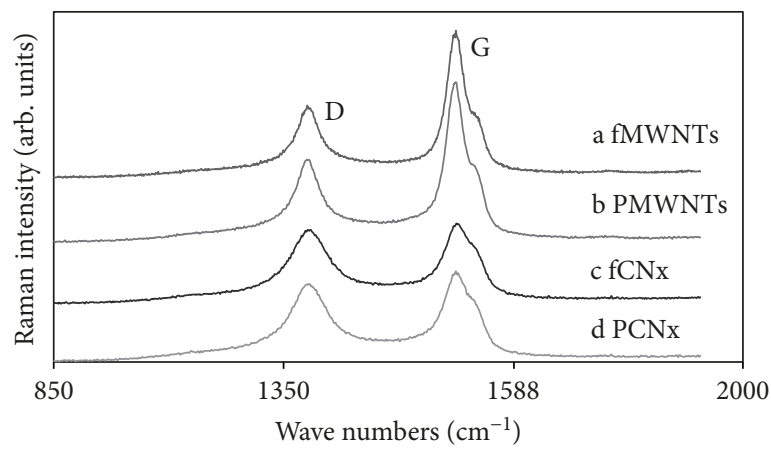

Figure 4: Raman spectra of CNTs using a laser exciting line of $633 \mathrm{~nm}$. G and D bands appears in all the samples at around $1588 \mathrm{~cm}^{-1}$ and $1350 \mathrm{~cm}^{-1}$, respectively.

and PCNxs. The $\mathrm{I}_{D} / \mathrm{I}_{G}$ ratios of fMWCNTs and fCNxs are $\sim 0.41$ and $\sim 0.89$, respectively, while the ratio of PMWNTs and PCNxs are $\sim 0.43$ and $\sim 0.82$, respectively (Table 1); results derived from the mechanism of oxidation during functionalization, more effective for the external walls of the CNxs.

The chemical compositions of the 4 types of nanotubes were further confirmed by IR spectroscopy (Figure 3). All the samples show the main absorbance bands between 1750 and $2200 \mathrm{~cm}^{-1}$, related to the $\mathrm{C}-\mathrm{C}$ bonds of the CNT 


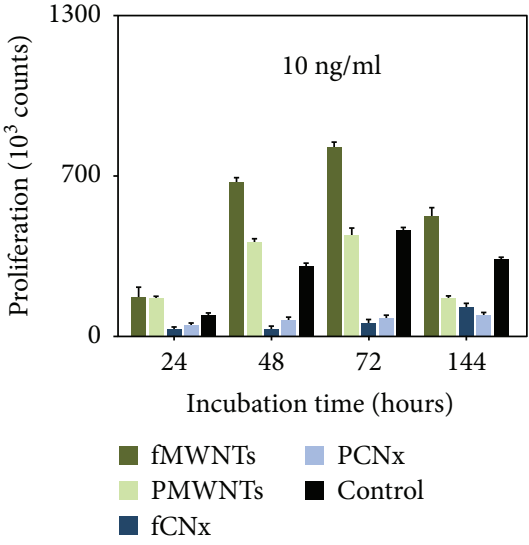

(a)

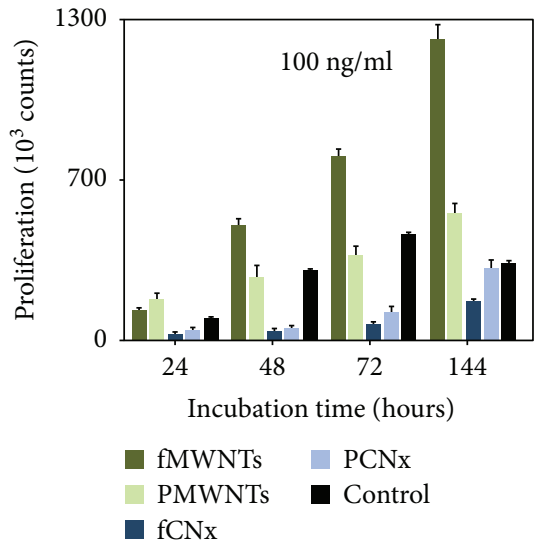

(b)

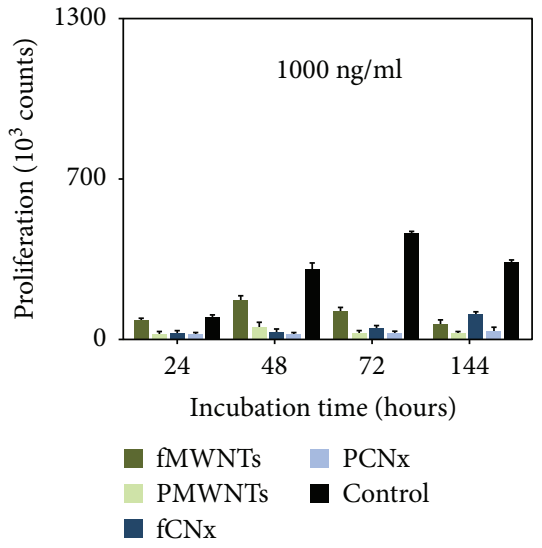

(c)

Figure 5: Bar plots of the proliferation effects on MSCs versus incubation time at different CNT concentrations for the four types of CNTs and a control sample. At concentrations of 10 and $100 \mathrm{ng} / \mathrm{ml}$, fMWNTs and PMWNTs promote cell proliferation; contrarily, fCNxs and PCNx causes inhibition. A 1000 all CNTs show a cytotoxic effect. The trypan blue escalation was performed to evaluate the cell viability. Data are representative of three independent experiments and are expressed as the mean of at least three experiments with $p<0.05$.

structure. While an increase in the intensity of this band is found in Figure 3(b) and (d) due to the bonds of the polymer, the carbonyl groups of the $\mathrm{OH}$ bands, obtained from the functionalization, are slightly marked at $2500 \mathrm{~cm}^{-1}$ in the 4 samples. The broad absorbance bands of PMWNTs and PCNxs (Figure $3(\mathrm{~b}-\mathrm{c})$ ) around 3200 and $3500 \mathrm{~cm}^{-1}$ are related to the $\mathrm{OH}$ associated with acidic and alcoholic hydroxyl functional groups of the polymer [28, 29]. After SEM, TEM, and Raman characterization, confirming the structure of the functionalized and polymerized nanotubes, the IR results shown in Figure 3, consistent with the literature $[28,29,31]$, further confirm the adequate functionalization and polymerization performed on the CNTs used in this experiment. Furthermore, data from thermal gravimetric analysis (TGA) (not shown) indicates that the amount of carboxylic acid groups and PCA bound to the CNTs do not change with the temperature rise; all the samples keeping a constant weight in the range from $15^{\circ} \mathrm{C}$ to $200^{\circ} \mathrm{C}$ with only $1 \%$ of variation, consistent with Vicente et al. [45]. Taking into account that the temperature required for the biomedical experiments is between 25 and $45^{\circ} \mathrm{C}$, the TGA results ensure that if for some reason there are temperature fluctuations during the process, the chemical conformation of CNTs is not affected.

3.2. Biological Assays. Once the different CNT samples were characterized, we proceeded to carry out the biological assays with derived rat bone marrow MSCs as primary cultures. The effect on cell proliferation of MSCs for different concentrations of CNTs is shown in Figure 5. At $10 \mathrm{ng} / \mathrm{ml}$ (Figure 5(a)), the most significant proliferative result comes from fMWNTs, which in comparison with the control sample, almost doubles the amount of cells at 48 and 72 hours. PMWNTs show less proliferation with similar behavior with respect to the control sample at $10 \mathrm{ng} / \mathrm{ml}$ for both 48 and 72 hrs. In contrast, fCNxs and PCNxs do not show proliferative capability at $10 \mathrm{ng} / \mathrm{ml}$. At $100 \mathrm{ng} / \mathrm{ml}$ (Figure 5(b)), fMWNTs and PMWNTs present a high proliferative growth behavior. In contrast, fCNxs and $\mathrm{PCNxs}$ remain with a lower proliferative capacity than the control sample at all times. Using the highest concentration, $1000 \mathrm{ng} / \mathrm{ml}$ (Figure 5(c)), it was remarkable that cell growth was not present in any sample, with the exception of the control one. The results of proliferative analysis for fMWNTs and PMWNTs differ with the behavior reported by Jiang et al. for PEGylated MWNTs in macrophage model cells [47], with our MWNTs showing a higher proliferative rate than the macrophage cells. In order to demonstrate whether cells incubated with fCNXs and PCNXs were dying or not proliferating, an apoptosis assay by flow cytometry using the same concentrations was performed, quantifying annexin V. From the apoptosis results of the $10 \mathrm{ng} / \mathrm{ml}$ concentration (Figure 6(a)), it is evident from the beginning of the experiment that fCNxs cause cell death. The effect of the polymer is clear, with PCNxs presenting a lower level of apoptosis than fCNxs. The apoptotic tendency of fCNxs is confirmed by the proliferative assay shown in Figure 5(a), where at the same concentration and time, both fCNxs and PCNxs do not proliferate in comparison with the control sample. The cytotoxicity of CNxs could be related to the high degree of defects confirmed by the $\mathrm{I}_{D} / \mathrm{I}_{G}$ ratio (Table 1 ). Correspondingly, at $10 \mathrm{ng} / \mathrm{ml}$, fMWNTs generate apoptotic behavior in a similar relation to the control, while PWNTs present a lower apoptotic behavior; that is, fMWNTs and PMWNTs induces higher proliferative capacity in contrast to fCNxs and PCNxs (Figure 5(a)). The apoptotic behavior of fCNxs at $100 \mathrm{ng} / \mathrm{ml}$ is the highest among the four types of CNT solutions (Figure 6(b)), similar to the behavior at $10 \mathrm{ng} / \mathrm{ml}$. PCNxs at $100 \mathrm{ng} / \mathrm{ml}$ also present low apoptotic behavior with respect to fCNxs, in comparison with the $10 \mathrm{ng} / \mathrm{ml}$ concentration still presenting a higher apoptotic percentage in contrast to the positive control. Accordingly, the proliferative behavior of both fCNxs and PCNxs at $100 \mathrm{ng} / \mathrm{ml}$ always presents lower levels than untreated cells. Thus, it is very significant that for all CNxs, when inducing apoptosis, its proliferative capability decreases. In contrast, 


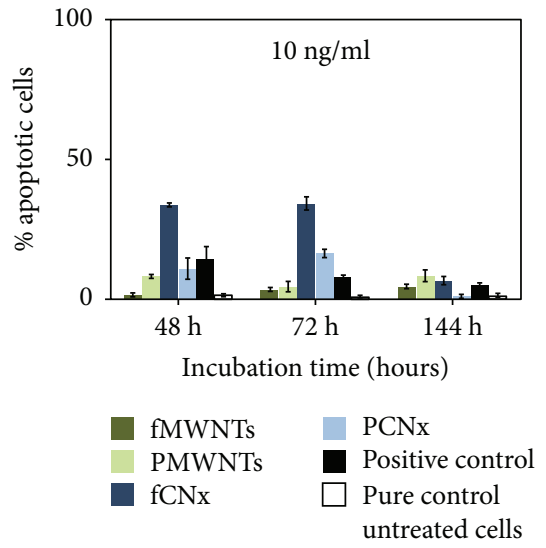

(a)

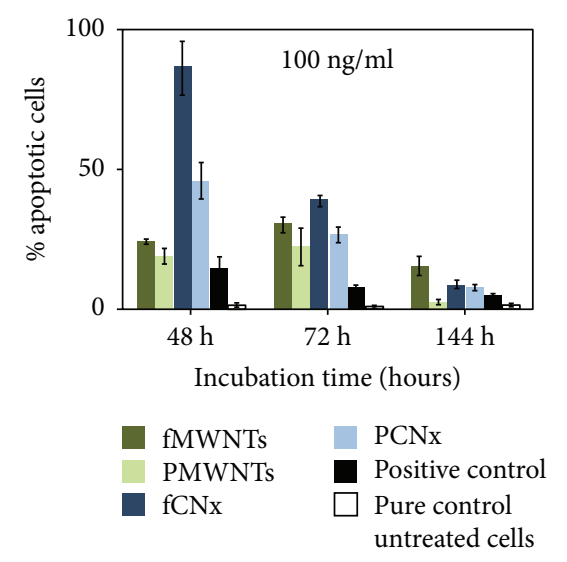

(b)

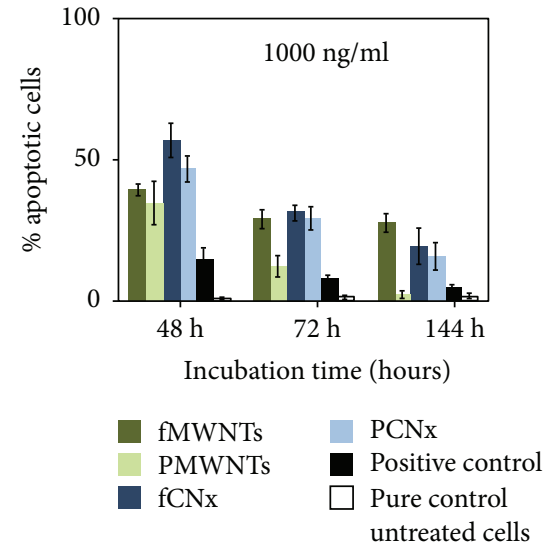

(c)

FIgure 6: Apoptosis evaluation. fMWNTs, PMWNTs, fCNxs, and PCNxs induced apoptosis at the MSCs in comparison with the positive control and the pure control of untreated cells at CNT concentrations of $10 \mathrm{ng} / \mathrm{ml}$ (a), $100 \mathrm{ng} / \mathrm{ml}$ (b), and $1000 \mathrm{ng} / \mathrm{ml}$ (c). Apoptosis was evaluated by an Annexin/propidium iodide assay kit using a flow cytometry, determining death cell by activation of Annexin V.

fMWNTs and PMWNTs, at $100 \mathrm{ng} / \mathrm{ml}$, present a higher apoptotic level than the positive control (still lower than fCNxs and PCNxs). In spite of this, their proliferative tendency does not diminish, increasing at all times; that is, their proliferation is activated in a significant way, particularly for fMWNT treatment. It seems that MSCs at $100 \mathrm{ng} / \mathrm{ml}$ of MWNTs show resistance to cell death and even enhance their proliferation. As time passes for the $100 \mathrm{ng} / \mathrm{ml}$ concentration, proliferation increases in all cases and the apoptosis decreases (Figures 5(b) and 6(b)). Remarkably, the PMWNT solution presents the lowest apoptotic induction and a high proliferative capacity for all times, including the 144-hour assay. Kroustalli et al. [54] reported similar results, showing that PMWNTs support adhesion and proliferation of hMSCs. Other studies indicate that polymerized CNTs present less impact in the activation of the oxidative responsible for the apoptotic pathway [55-57].

Finally, at the highest concentration of $1000 \mathrm{ng} / \mathrm{ml}$ shown in Figures 5(c) and 6(c), all the samples showed the lowest proliferative capacities sharing the same apoptotic tendencies and the same cytotoxic effects. Interestingly, the most significant results for both proliferation and apoptosis assays are at concentrations of $100 \mathrm{ng} / \mathrm{ml}$ (shown in Figures 5(b) and 6(b), respectively, and proved statistically by three independent experiments, showing high proliferation and apoptosis for MWNTs and CNxs, respectively. The next step was to analyze by confocal microscopy the behavior of MSCs in cultures performed with CNTs from each group, focusing mainly in the $100 \mathrm{ng} / \mathrm{ml}$ concentration. Figure 7 shows the evaluation of cellular morphology and intracellular incorporation of external agents for the cultured MSCs with CNT solutions at $100 \mathrm{ng} / \mathrm{ml}$. Starting with the behavior of the control sample for reference in Figure 7(a) (i-iv), a standard nuclear morphology is observed in the red fluorescence channel (Figure 7(a) (i)). Since no CNTs are present in the control, no fluorescence from CNTs is observed in the green channel of Figure 7(a) (ii); the match for both channels only presents the red fluorescence with a normal morphology of the whole cell, observed in the visible light channel of panel (iv) of Figure 7(a)). The effects of $100 \mathrm{ng} / \mathrm{ml}$ solutions for all CNTs, fMWNTs, PMWNTs, fCNxs, and PCNxs, are shown in Figures $7(\mathrm{~b})-7(\mathrm{e})$, respectively. Panels (i) of Figures 7(b) and $7(\mathrm{~d})$ correspond to the red fluorescence from fMWNTs and fCNxs, respectively, both showing an apoptotic behavior represented by the nuclear destruction indicated by white circles. In comparison, PMWNTs and PCNxs, in panels (i) of Figures 7(c) and 7(e), respectively, show a well-ordered nucleus, morphologically identical to the control (Figure 7(a) (i)); a clear evidence that the PCA polymerization reduces the apoptotic behavior of $\mathrm{fCNx}$ as shown in Figure 6(b)).

Panels (ii) in Figures 7(b)-7(e) show the green fluorescence of the corresponding nanotubes inside the MSCs. Particularly, in the case of fMWNTs and fCNxs, shown in Figures $7(\mathrm{~b})$ and $7(\mathrm{~d})$, there is an evident presence of nanotubes in green, indicated by white arrows.

Panels (iii) in Figure 7 result from merging the red and green channels, corresponding to panels (i) and (ii), illustrating the exact position of the nanotubes with respect to the nucleus. Finally, visible light panels (iv) are included, where the fibrillar structure of fMWNTs and fCNxs are clearly shown inside the cells. In addition to apoptosis decrease in treated cells with PMWNTs, it is interesting that these CNTs in a major quantity remain around and out of cell (Figure 8).

\section{Discussion}

The uptake mechanism for carbon nanotubes has been explored [58]; seemingly, functionalization impacts directly regarding MWCNTs uptake mechanisms [59]. MWCNTs are internalized according to their diameter and length ratios as well as their size and concentration within the milieu [60]. Accordingly, as shown in Figures 7(b) and 7(d), fMWNTs and fCNxs localize inside the cell, a similar situation to that reported by Adeli et al. However, because of a structural and chemical modification, adding PCA, PMWNTs, and PCNxs is encountered in fewer occasions 

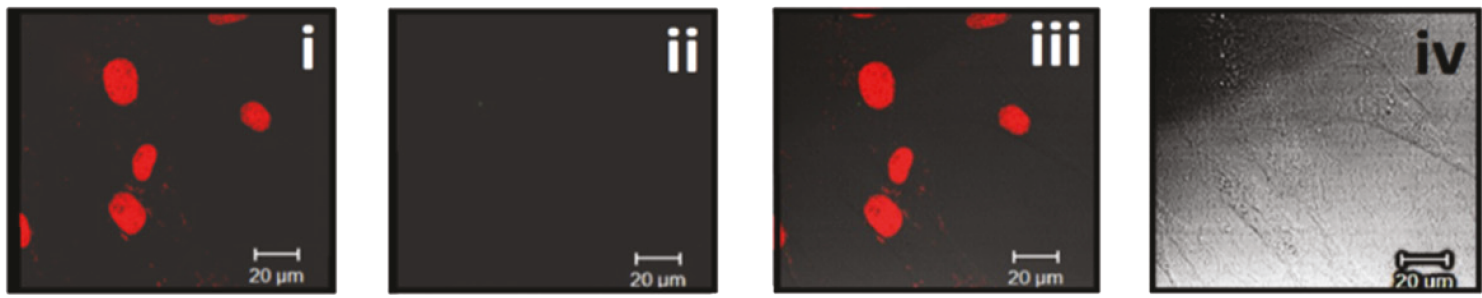

(a)
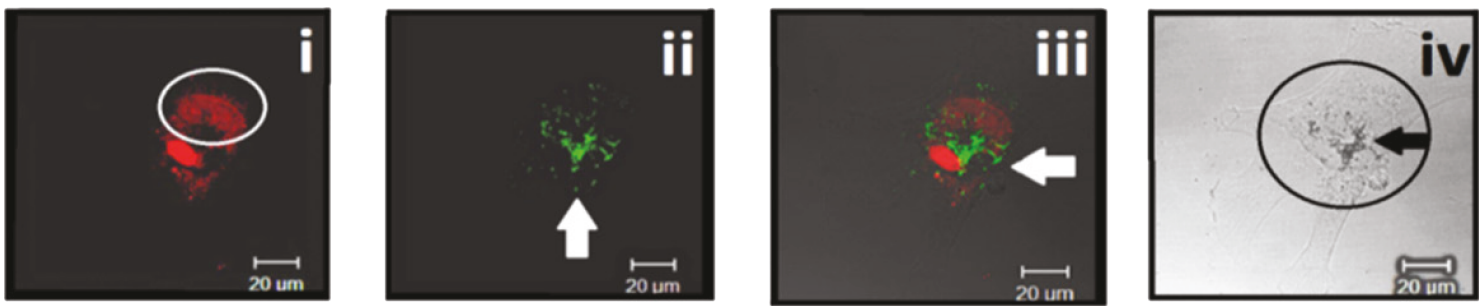

(b)
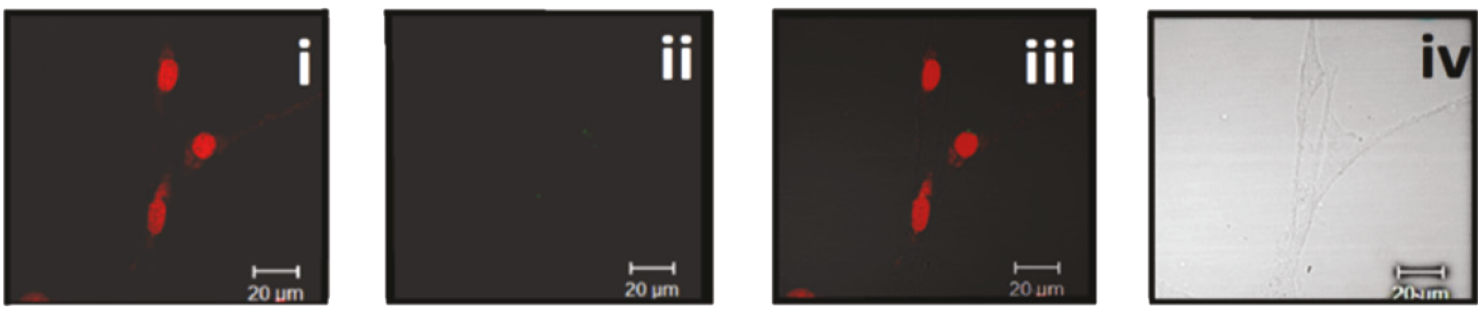

(c)
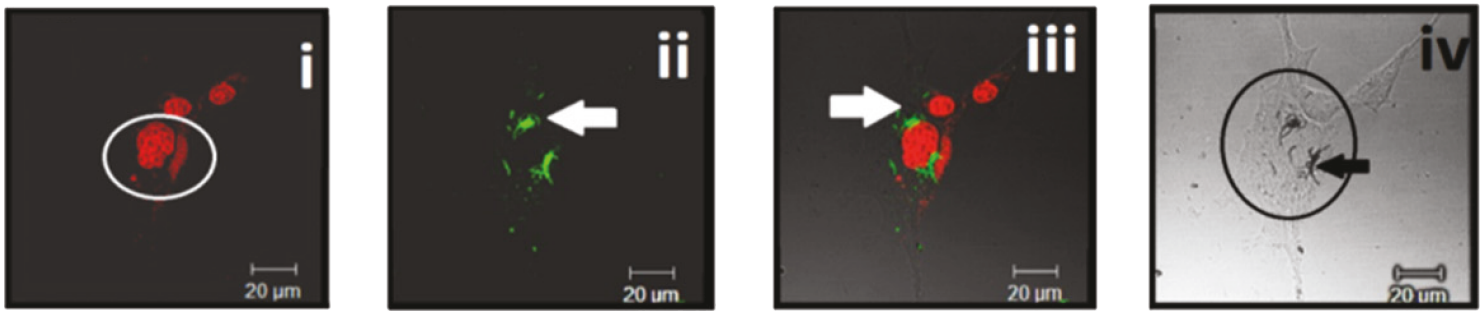

(d)
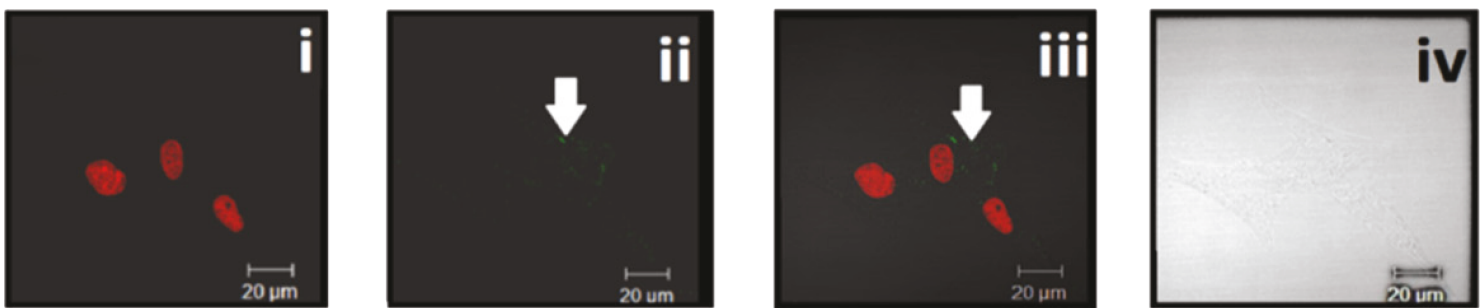

(e)

FIgURE 7: Confocal microscope images of the MSC cells incubated during 72 hours in the $100 \mathrm{ng} / \mathrm{ml}$ solution for each type of nanotube. (a) Control sample showing the red fluorescence field (at $488 \mathrm{~nm}$ ) where the nuclei morphology is unaffected (i), the green fluorescence (at $633 \mathrm{~nm}$ ) of CNTs with no trace of them (ii), the match of (i) and (ii) in (iii), and the bright field of the sample (iv). White arrows in panels (b-e) show the intracellular distribution of fMWNTs (b), PMWNTs (c), fCNxs (d), and PCNxs (e). Panels (i) show the red fluorescence field, illustrating the nuclei morphology; the white circles in (b, i) and (d, i) show apoptotic nuclei. Panels (ii) show green fluorescence of CNTs with clear nanotube presence in the fMWNT and fCNx samples (b, ii) and (d, ii), respectively. Panels (iii) show the match of (i) and (ii). Panels (iv) show the bright field where fMWNTs and fCNxs clearly present the fibrillar structure of the CNTs inside the MSCs.

inside the cells as compared to nonPCAylated CNTs, although they present the required dimensions to be incorporated. The fact that PMWNTs and PCNxs do not enter the cell can be attributed to the high presence of oxygenated groups, like those encountered in the hyperbranched PCA surfaces, which interact with proteins of the extracellular 


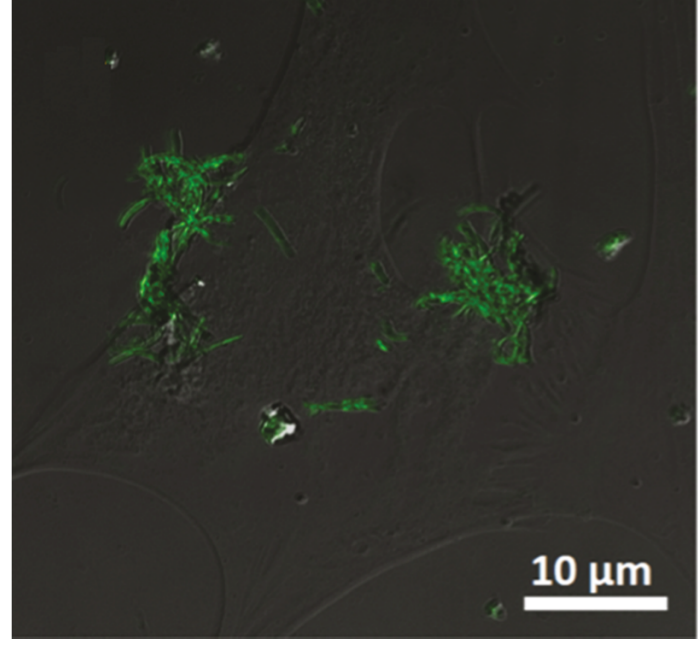

FIgURE 8: PMWNTs in contact with a MSC. Unlike the rest of the CNTs analyzed in cell cultures, the PMWNTs are in contact with the cells and mostly remain outside the cell.

matrix, reducing the cellular endocytosis mechanism [55]. Figure 8 reinforces the fact that the polymerized nanotubes enter the cell in lower amount than functionalized nanotubes, remaining in the periphery. This fact is relevant, because it would allow the MSCs have better capacity to adhere to tissue to which they are intended, once they are pretreated with PWCNT.

The effect on the morphology of the MSCs, in contact with PMWNTs and PCNxs, does not present major changes, contrasting with the results of hyperbranched polymers like PEG, reported by Murphy et al. $[18,61]$.

A subject of great relevance is to continue the study of the interaction between PCNTs and MSCs, but there are some interesting questions to answer beforehand, for example, can the interaction between PMWNTs and MSCs induce growth factors and secretion of substances from the cells? $[18,62]$. Can the polymer interact with molecules found in the extracellular matrix [61-64], such as glycoproteins? Will this allow binding to a range of growth receptors with high affinity [18] or simply increase the adhesive capacity of the material? [54, 65, 66].

Although the initial objective of this work was to evaluate the cytotoxicity of CNT functionalized and polymerized in MSC in culture, as has been done, our study opens new fields in cell biology research for possible CNT applications modified for cell grafts.

Given these results, fCNTs entering the cell $[16,58,67,68]$ adhere to growing evidence for the fCNTs to be used as drug carrier vehicles $[58,67-72]$ in cancer therapy $[55,67,70,72]$, as well as for studies of cytotoxic effects [55, 58-60, 73-76]. The green fluorescence of the confocal images inside the cells confirms the fCNx uptake, a phenomenon that can be used for optical stimulation of CNTs inside living cells to afford multifunctional biological transporters of CNTs. Thus, the transporting capacity of CNTs combined with a suitable chemistry functionalization and their intrinsic optical properties can lead to novel nanomaterials for drug delivery and cancer therapy.
With the perspective of scaffolding production and design [77-79], CNTs coated with PCA may provide a clear advantage for the design of scaffolds; coated CNTs do not cause intracellular damage, because the PMWNTs cannot be internalized inside cells. So, scaffolds produced with PCNTs could be able to promote novel tissue formation, favoring cell adhesion and proliferation. Related to our results is the suggestion to use nanotube-based films linked by a bi- or tridimensional network of PCA to prevent individual nanotubes from being dislodged and entering the cell, expecting to resemble the tissue extracellular matrix [77-79], providing adequate structural support and favoring a good biomedical development.

Finally, to continue the analysis of carbon materials with the presence of MSCs, the use of PCA-polymerized graphene structures could be proposed as a biomaterial [80], hoping that graphene properties could provide different and interesting cellular responses.

\section{Conclusion}

This is the first time that PCA-polymerized CNTs have been used with MSCs to fix to the cellular matrix, whose result is positive and offers stability scaffold on MCS cells, having ample possibilities to generate a bridge between cells and tissues through which could facilitate the adherence of MSC directly to tissue in cell regeneration processes. An additional advantage is that nanotubes do not interfere on morphological process because the MSCs in contact with PMWNTs and PCNxs do not present major changes, in comparison with other type of hyperbranched polymerized CNTs. Our results show that apoptotic and proliferative behavior is similar between cells treated with fCNxs and PCNxs (Figure 5), presenting the lowest proliferative rates and the highest apoptotic levels (Figure 6). Functionalized and polymerized MWNTs present a higher proliferative rate and relatively low apoptotic behavior (at $100 \mathrm{ng} / \mathrm{ml}$ ). According to the results, possible applications of the tested nanotubes in this work are proposed: fCNxs and PCNxs possibly suitable for the transport of substances inside the cell. fMWNTs and PMWNTs were proposed as viable materials for possible biomedical applications as cellular scaffolding.

\section{Conflicts of Interest}

The authors declare that they have no conflicts of interest.

\section{Acknowledgments}

Rosa L. Garnica-Gutiérrez thanks Felix Martínez and the Engineering Faculty of Universidad Panamericana for their support during the project. Salomón Hernández-Gutiérrez thanks funding from the CONACYT-Project 101596. Felipe Cervantes-Sodi thanks funding from the Physics and Mathematics Department, the Research Direction and FICSAC, UIA. Authors are thankful to S. Rosas-Meléndez, M. Ballesteros-Villareal, F. A. Iñiguez-Rábago. S. Macias, R. Estrada, and V. Garibay-Febles for fruitful discussions and support with experiments and characterization. 


\section{References}

[1] F. Cardano, M. Frasconi, and S. Giordani, "Photo-responsive graphene and carbon nanotubes to control and tackle biological systems," Frontiers in Chemistry, vol. 6, p. 102, 2018.

[2] S. Gupta, C. N. Murthy, and C. R. Prabha, "Recent advances in carbon nanotube based electrochemical biosensors," International Journal of Biological Macromolecules, vol. 108, pp. 687-703, 2018.

[3] N. L. Teradal and R. Jelinek, "Carbon nanomaterials in biological studies and biomedicine," Advanced Healthcare Materials, vol. 6, no. 17, 2017.

[4] U. A. Ashfaq, M. Riaz, E. Yasmeen, and M. Z. Yousaf, "Recent advances in nanoparticle-based targeted drug-delivery systems against cancer and role of tumor microenvironment," Critical Reviews in Therapeutic Drug Carrier Systems, vol. 34, no. 4, pp. 317-353, 2017.

[5] J. Pardo, Z. Peng, and R. Leblanc, "Cancer targeting and drug delivery using carbon-based quantum dots and nanotubes," Molecules, vol. 23, no. 2, p. 378, 2018.

[6] M. Mir, S. Ishtiaq, S. Rabia et al., "Nanotechnology: from in vivo imaging system to controlled drug delivery," Nanoscale Research Letters, vol. 12, no. 1, p. 500, 2017.

[7] L. Krishna, K. Dhamodaran, C. Jayadev et al., "Nanostructured scaffold as a determinant of stem cell fate," Stem Cell Research \& Therapy, vol. 7, no. 1, p. 188, 2016.

[8] E.-S. Kang, D. S. Kim, I. R. Suhito et al., "Guiding osteogenesis of mesenchymal stem cells using carbon-based nanomaterials," Nano Convergence, vol. 4, no. 1, p. 2, 2017.

[9] C. Gao, P. Feng, S. Peng, and C. Shuai, "Carbon nanotube, graphene and boron nitride nanotube reinforced bioactive ceramics for bone repair," Acta Biomaterialia, vol. 61, pp. 1-20, 2017.

[10] H. P. Boehm, "Surface oxides on carbon and their analysis: a critical assessment," Carbon, vol. 40, no. 2, pp. 145-149, 2002.

[11] M. Kovochich, C.-C. D. Fung, R. Avanasi, and A. K. Madl, "Review of techniques and studies characterizing the release of carbon nanotubes from nanocomposites: implications for exposure and human health risk assessment," Journal of Exposure Science and Environmental Epidemiology, vol. 28, no. 3, pp. 203-215, 2017.

[12] A. O. Elzoghby, A. L. Hemasa, and M. S. Freag, "Hybrid protein-inorganic nanoparticles: from tumor-targeted drug delivery to cancer imaging," Journal of Controlled Release, vol. 243, pp. 303-322, 2016.

[13] M. A. Correa-Duarte, N. Wagner, J. Rojas-Chapana, C. Morsczeck, M. Thie, and M. Giersig, "Fabrication and biocompatibility of carbon nanotube-based $3 \mathrm{~d}$ networks as scaffolds for cell seeding and growth," Nano Letters, vol. 4, no. 11, pp. 2233-2236, 2004.

[14] D. Gutiérrez-Praena, S. Pichardo, E. Sánchez, A. Grilo, A. M. Cameán, and A. Jos, "Influence of carboxylic acid functionalization on the cytotoxic effects induced by single wall carbon nanotubes on human endothelial cells (huvec)," Toxicology In Vitro, vol. 25, no. 8, pp. 1883-1888, 2011.

[15] H. Isobe, T. Tanaka, R. Maeda et al., "Preparation, purification, characterization, and cytotoxicity assessment of water-soluble, transition-metal-free carbon nanotube aggregates," Angewandte Chemie, vol. 118, no. 40, pp. 6828-6832, 2006.

[16] M. Adeli, R. Soleyman, Z. Beiranvand, and F. Madani, "Carbon nanotubes in cancer therapy: a more precise look at the role of carbon nanotube-polymer interactions," Chemical Society Reviews, vol. 42, no. 12, pp. 5231-5256, 2013.

[17] M. Adeli, N. Mirab, M. S. Alavidjeh, Z. Sobhani, and F. Atyabi, "Carbon nanotubes-graft-polyglycerol: biocompatible hybrid materials for nanomedicine," Polymer, vol. 50, no. 15, pp. 3528-3536, 2009.

[18] W. L. Murphy, T. C. McDevitt, and A. J. Engler, "Materials as stem cell regulators," Nature Materials, vol. 13, no. 6, pp. 547-557, 2014.

[19] M. Assali, A. N. Zaid, N. Kittana, D. Hamad, and J. Amer, "Covalent functionalization of swcnt with combretastatin a4 for cancer therapy," Nanotechnology, vol. 29, no. 24, article 245101, 2018.

[20] Y. Gustafsson, J. Haag, P. Jungebluth et al., "Viability and proliferation of rat mscs on adhesion protein-modified pet and pu scaffolds," Biomaterials, vol. 33, no. 32, pp. 80948103, 2012.

[21] S. Varghese, N. S. Hwang, A. C. Canver, P. Theprungsirikul, D. W. Lin, and J. Elisseeff, "Chondroitin sulfate based niches for chondrogenic differentiation of mesenchymal stem cells," Matrix Biology, vol. 27, no. 1, pp. 12-21, 2008.

[22] C. Zhao, H. Andersen, B. Ozyilmaz, S. Ramaprabhu, G. Pastorin, and H. K. Ho, "Spontaneous and specific myogenic differentiation of human mesenchymal stem cells on polyethylene glycol-linked multi-walled carbon nanotube films for skeletal muscle engineering," Nanoscale, vol. 7, no. 43, pp. 18239-18249, 2015

[23] K. Bhattacharya, C. Sacchetti, P. M. Costa et al., "Nitric oxide dependent degradation of polyethylene glycol-modified single-walled carbon nanotubes: implications for intraarticular delivery," Advanced Healthcare Materials, vol. 7, no. 6, 2018.

[24] T. R. Nayak, L. Jian, L. C. Phua, H. K. Ho, Y. Ren, and G. Pastorin, "Thin films of functionalized multiwalled carbon nanotubes as suitable scaffold materials for stem cells proliferation and bone formation," ACS Nano, vol. 4, no. 12, pp. 7717-7725, 2010.

[25] H. Ahmadi, M. Ramezani, R. Yazdian-Robati et al., "Acute toxicity of functionalized single wall carbon nanotubes: a biochemical, histopathologic and proteomics approach," Chemico-Biological Interactions, vol. 275, pp. 196-209, 2017.

[26] N. Sarlak, M. Adeli, M. Karimi, M. Bordbare, and M. A. Farahmandnejad, "Quantitative study on the interaction of ag+ and pd2+ with cnt-graft-pca (polycitric acid) in aqueous solution," Journal of Molecular Liquids, vol. 180, pp. 3944, 2013.

[27] A. Bahari, H. Hekmatara, R. Sepahvand, and M. Adeli, "Carbon nanotube-graft-poly (citric acid) containing silver and palladium nanoparticles," Nano, vol. 4, no. 4, pp. $217-$ 223, 2009.

[28] M. Adeli, A. Bahari, and H. Hekmatara, "Carbon nanotubegraft-poly (citric acid) nanocomposites," Nano, vol. 3, no. 1, pp. 37-44, 2008.

[29] R. K. Kainthan, S. R. Hester, E. Levin, D. V. Devine, and D. E. Brooks, "In vitro biological evaluation of high molecular weight hyperbranched polyglycerols," Biomaterials, vol. 28, no. 31, pp. 4581-4590, 2007.

[30] F. Atyabi, Sobhani, M. Adeli, R. Dinarvand, and Ghahremani, "Increased paclitaxel cytotoxicity against cancer cell lines using a novel functionalized carbon nanotube," International Journal of Nanomedicine, vol. 6, pp. 705-719, 2011. 
[31] B. Zhao, H. Hu, A. Yu, D. Perea, and R. C. Haddon, "Synthesis and characterization of water soluble single-walled carbon nanotube graft copolymers," Journal of the American Chemical Society, vol. 127, no. 22, pp. 8197-8203, 2005.

[32] E. Heister, E. W. Brunner, G. R. Dieckmann, I. Jurewicz, and A. B. Dalton, "Are carbon nanotubes a natural solution? Applications in biology and medicine," ACS Applied Materials \& Interfaces, vol. 5, no. 6, pp. 1870-1891, 2013.

[33] M. J. Dalby, N. Gadegaard, R. Tare et al., "The control of human mesenchymal cell differentiation using nanoscale symmetry and disorder," Nature Materials, vol. 6, no. 12, pp. 997-1003, 2007.

[34] Y. Cho, N. Shin, D. Kim, J. Y. Park, and S. Hong, "Nanoscale hybrid systems based on carbon nanotubes for biological sensing and control," Bioscience Reports, vol. 37, no. 2, article BSR20160330, 2017.

[35] A. J. Engler, S. Sen, H. L. Sweeney, and D. E. Discher, "Matrix elasticity directs stem cell lineage specification," Cell, vol. 126, no. 4, pp. 677-689, 2006.

[36] C. P. Hodgkinson, J. A. Gomez, M. Mirotsou, and V. J. Dzau, "Genetic engineering of mesenchymal stem cells and its application in human disease therapy," Human Gene Therapy, vol. 21, no. 11, pp. 1513-1526, 2010.

[37] J. Lee, A. A. Abdeen, D. Zhang, and K. A. Kilian, "Directing stem cell fate on hydrogel substrates by controlling cell geometry, matrix mechanics and adhesion ligand composition," Biomaterials, vol. 34, no. 33, pp. 81408148, 2013.

[38] P. Bot, I. Hoefer, J. Piek, and G. Pasterkamp, "Hyaluronic acid: targeting immune modulatory components of the extracellular matrix in atherosclerosis," Current Medicinal Chemistry, vol. 15, no. 8, pp. 786-791, 2008.

[39] E. Beltrán-Partida, B. Valdéz-Salas, A. Moreno-Ulloa et al., "Improved in vitro angiogenic behavior on anodized titanium dioxide nanotubes," Journal of Nanobiotechnology, vol. 15, no. 1, p. 10, 2017.

[40] M. Sheikholeslam, S. D. Wheeler, K. G. Duke, M. Marsden, M. Pritzker, and P. Chen, "Peptide and peptide-carbon nanotube hydrogels as scaffolds for tissue \& 3d tumor engineering," Acta Biomaterialia, vol. 69, pp. 107-119, 2018.

[41] P. Tsimbouri, N. Gadegaard, K. Burgess et al., "Nanotopographical effects on mesenchymal stem cell morphology and phenotype," Journal of Cellular Biochemistry, vol. 115, no. 2, pp. 380-390, 2014.

[42] S. Khetan, M. Guvendiren, W. R. Legant, D. M. Cohen, C. S. Chen, and J. A. Burdick, "Degradation-mediated cellular traction directs stem cell fate in covalently crosslinked threedimensional hydrogels," Nature Materials, vol. 12, no. 5, pp. 458-465, 2013.

[43] S. Miyagawa, Y. Sawa, S. Sakakida et al., "Tissue cardiomyoplasty using bioengineered contractile cardiomyocyte sheets to repair damaged myocardium: their integration with recipient myocardium," Transplantation, vol. 80, no. 11, pp. 15861595, 2005.

[44] A. Botello-Méndez, J. Campos-Delgado, A. Morelos-Gómez et al., "Controlling the dimensions, reactivity and crystallinity of multiwalled carbon nanotubes using low ethanol concentrations," Chemical Physics Letters, vol. 453, no. 1-3, pp. 55-61, 2008.

[45] J. L. Vicente, A. Albesa, J. Lianos et al., "Effect of acid oxidation treatment on adsorption properties of arc-discharge synthesized multiwall carbon nanotubes," Journal of the Argentine Chemical Society, vol. 98, pp. 29-38, 2011.

[46] J. Liu, A. G. Rinzler, H. Dai et al., "Fullerene pipes," Science, vol. 280, no. 5367, pp. 1253-1256, 1998.

[47] Y. Jiang, H. Zhang, Y. Wang et al., "Modulation of apoptotic pathways of macrophages by surface-functionalized multiwalled carbon nanotubes," PLoS One, vol. 8, no. 6, article e65756, 2013.

[48] M. Terrones, A. G. Souza Filho, and A. M. Rao, "Doped carbon nanotubes: synthesis, characterization and applications," in Carbon nanotubes, pp. 531-566, Springer, 2007.

[49] K. Gong, F. Du, Z. Xia, M. Durstock, and L. Dai, "Nitrogendoped carbon nanotube arrays with high electrocatalytic activity for oxygen reduction," Science, vol. 323, no. 5915, pp. 760-764, 2009.

[50] C. Bower, A. Kleinhammes, Y. Wu, and O. Zhou, "Intercalation and partial exfoliation of single-walled carbon nanotubes by nitric acid," Chemical Physics Letters, vol. 288, no. 2-4, pp. 481-486, 1998.

[51] M. S. Dresselhaus, G. Dresselhaus, and P. C. Eklund, Science of Fullerenes and Carbon Nanotubes: Their Properties and Applications, Elsevier, 1996.

[52] V. Datsyuk, M. Kalyva, K. Papagelis et al., "Chemical oxidation of multiwalled carbon nanotubes," Carbon, vol. 46, no. 6, pp. 833-840, 2008.

[53] U. Kuhlmann, H. Jantoljak, N. Pfänder, P. Bernier, C. Journet, and C. Thomsen, "Infrared active phonons in singlewalled carbon nanotubes," Chemical Physics Letters, vol. 294, no. 1-3, pp. 237-240, 1998.

[54] A. A. Kroustalli, S. N. Kourkouli, and D. D. Deligianni, "Cellular function and adhesion mechanisms of human bone marrow mesenchymal stem cells on multi-walled carbon nanotubes," Annals of Biomedical Engineering, vol. 41, no. 12, pp. 2655-2665, 2013.

[55] Y. Zhang, Y. Xu, Z. Li et al., "Mechanistic toxicity evaluation of uncoated and pegylated single-walled carbon nanotubes in neuronal pc12 cells," ACS Nano, vol. 5, no. 9, pp. 70207033, 2011.

[56] X. Wang, T. Xia, S. Addo Ntim et al., "Dispersal state of multiwalled carbon nanotubes elicits profibrogenic cellular responses that correlate with fibrogenesis biomarkers and fibrosis in the murine lung," ACS Nano, vol. 5, no. 12, pp. 9772-9787, 2011.

[57] L. Tabet, C. Bussy, A. Setyan et al., "Coating carbon nanotubes with a polystyrene-based polymer protects against pulmonary toxicity," Particle and Fibre Toxicology, vol. 8, no. 1, p. 3, 2011.

[58] C. Caoduro, E. Hervouet, C. Girard-Thernier et al., "Carbon nanotubes as gene carriers: focus on internalization pathways related to functionalization and properties," Acta Biomaterialia, vol. 49, pp. 36-44, 2017.

[59] C. L. Ursini, R. Maiello, A. Ciervo et al., "Evaluation of uptake, cytotoxicity and inflammatory effects in respiratory cells exposed to pristine and $-\mathrm{OH}$ and $-\mathrm{COOH}$ functionalized multi-wall carbon nanotubes," Journal of Applied Toxicology, vol. 36, no. 3, pp. 394-403, 2016.

[60] K. Maruyama, H. Haniu, N. Saito et al., "Endocytosis of multiwalled carbon nanotubes in bronchial epithelial and mesothelial cells," BioMed Research International, vol. 2015, Article ID 793186, 9 pages, 2015.

[61] D. D. Deligianni, "Multiwalled carbon nanotubes enhance human bone marrow mesenchymal stem cells' spreading but 
delay their proliferation in the direction of differentiation acceleration," Cell Adhesion \& Migration, vol. 8, no. 6, pp. 558-562, 2014.

[62] W. Bai, Z. Wu, S. Mitra, and J. M. Brown, "Effects of multiwalled carbon nanotube surface modification and purification on bovine serum albumin binding and biological responses," Journal of Nanomaterials, vol. 2016, Article ID 2159537, 10 pages, 2016.

[63] C. Del Gaudio, S. Baiguera, F. Ajalloueian, A. Bianco, and P. Macchiarini, "Are synthetic scaffolds suitable for the development of clinical tissue-engineered tubular organs?," Journal of Biomedical Materials Research Part A, vol. 102, no. 7, pp. 2427-2447, 2014.

[64] L. Liu, W. Wu, X. Tuo et al., "Novel strategy to engineer trachea cartilage graft with marrow mesenchymal stem cell macroaggregate and hydrolyzable scaffold," Artificial Organs, vol. 34, no. 5, pp. 426-433, 2010.

[65] D.-W. Kang, F. Sun, Y. J. Choi et al., "Enhancement of primary neuronal cell proliferation using printing-transferred carbon nanotube sheets," Journal of Biomedical Materials Research Part A, vol. 103, no. 5, pp. 1746-1754, 2015.

[66] A. M. Kloxin, A. M. Kasko, C. N. Salinas, and K. S. Anseth, "Photodegradable hydrogels for dynamic tuning of physical and chemical properties," Science, vol. 324, no. 5923, pp. 5963, 2009.

[67] A. Sanginario, B. Miccoli, and D. Demarchi, "Carbon nanotubes as an effective opportunity for cancer diagnosis and treatment," Biosensors, vol. 7, no. 4, p. 9, 2017.

[68] C.-M. Tîlmaciu and M. C. Morris, "Carbon nanotube biosensors," Frontiers in Chemistry, vol. 3, 2015.

[69] H. Wang, Q. Chen, and S. Zhou, "Carbon-based hybrid nanogels: a synergistic nanoplatform for combined biosensing, bioimaging, and responsive drug delivery," Chemical Society Reviews, vol. 47, no. 11, pp. 4198-4232, 2018.

[70] J. Zhang, H. Tang, Z. Liu, and B. Chen, "Effects of major parameters of nanoparticles on their physical and chemical properties and recent application of nanodrug delivery system in targeted chemotherapy," International Journal of Nanomedicine, vol. 12, pp. 8483-8493, 2017.

[71] A. Alibakhshi, F. Abarghooi Kahaki, S. Ahangarzadeh et al., "Targeted cancer therapy through antibody fragmentsdecorated nanomedicines," Journal of Controlled Release, vol. 268, pp. 323-334, 2017.

[72] F. u. Din, W. Aman, I. Ullah et al., "Effective use of nanocarriers as drug delivery systems for the treatment of selected tumors," International Journal of Nanomedicine, vol. 12, pp. 7291-7309, 2017.

[73] S. F. Larner, J. Wang, J. Goodman, M. B. O’Donoghue Altman, M. Xin, and K. K. W. Wang, "In vitro neurotoxicity resulting from exposure of cultured neural cells to several types of nanoparticles," Journal of Cell Death, vol. 10, 2017.

[74] A. Ali, M. Suhail, S. Mathew et al., "Nanomaterial induced immune responses and cytotoxicity," Journal of Nanoscience and Nanotechnology, vol. 16, no. 1, pp. 40-57, 2016.

[75] J. K. Fard, S. Jafari, and M. A. Eghbal, "A review of molecular mechanisms involved in toxicity of nanoparticles," Advanced Pharmaceutical Bulletin, vol. 5, no. 4, pp. 447-454, 2015.

[76] J. Dong and Q. Ma, "Advances in mechanisms and signaling pathways of carbon nanotube toxicity," Nanotoxicology, vol. 9, no. 5, pp. 658-676, 2015.
[77] N. Huebsch, P. R. Arany, A. S. Mao et al., "Harnessing traction-mediated manipulation of the cell/matrix interface to control stem-cell fate," Nature Materials, vol. 9, no. 6, pp. 518-526, 2010.

[78] B. Trappmann, J. E. Gautrot, J. T. Connelly et al., "Extracellular-matrix tethering regulates stem-cell fate," Nature Materials, vol. 11, no. 7, pp. 642-649, 2012.

[79] X. Li, H. Liu, X. Niu et al., "The use of carbon nanotubes to induce osteogenic differentiation of human adipose-derived mscs in vitro and ectopic bone formation in vivo," Biomaterials, vol. 33, no. 19, pp. 4818-4827, 2012.

[80] N. Li, Q. Zhang, S. Gao et al., "Three-dimensional graphene foam as a biocompatible and conductive scaffold for neural stem cells," Scientific Reports, vol. 3, no. 1, p. 1604, 2013. 


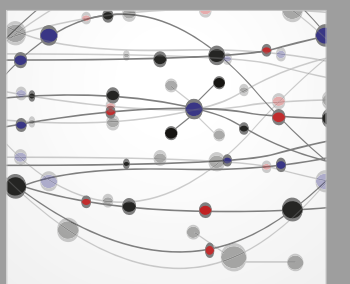

The Scientific World Journal
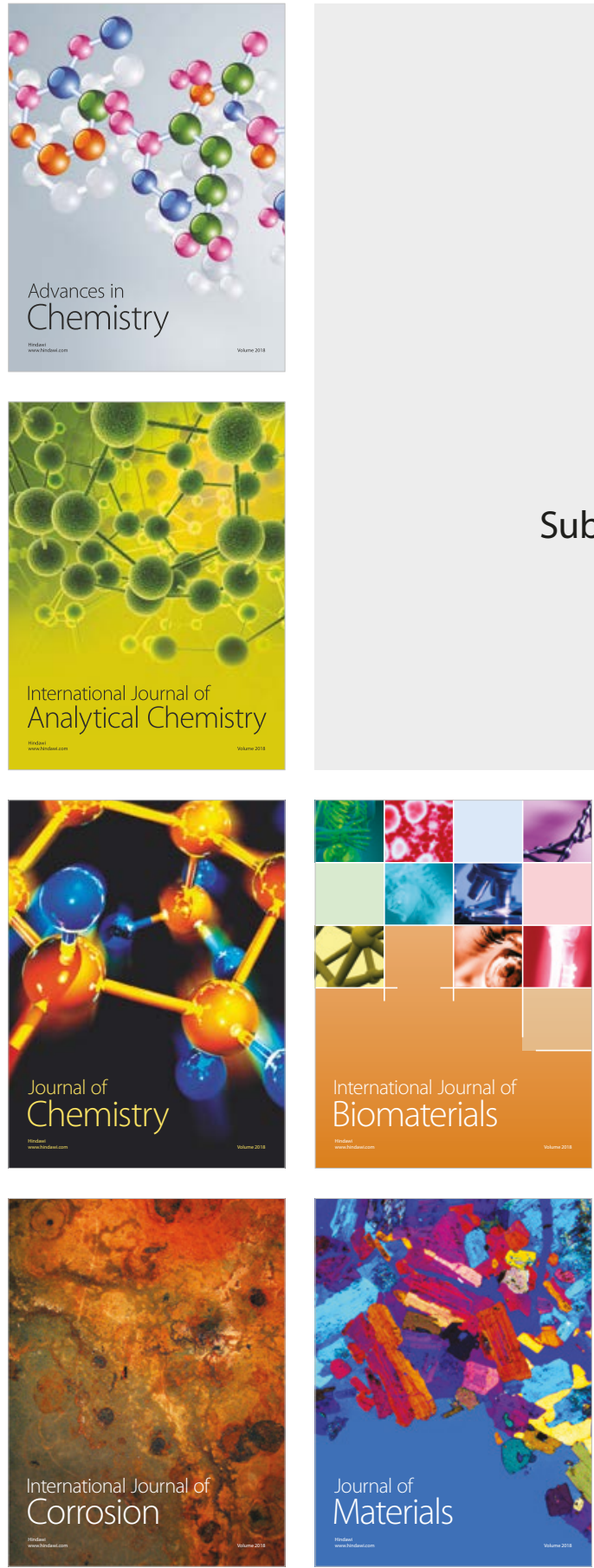

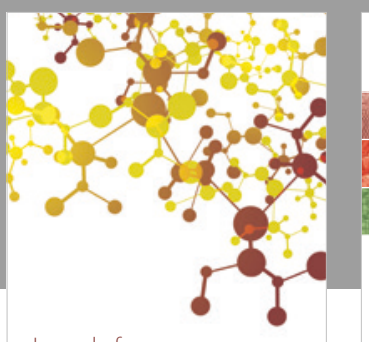

Journal of

Applied Chemistry
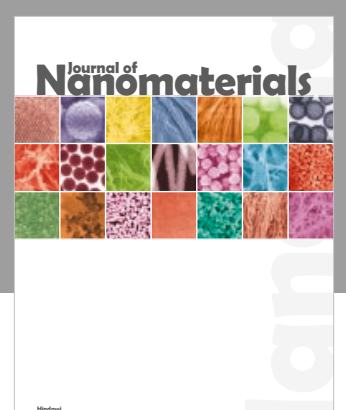

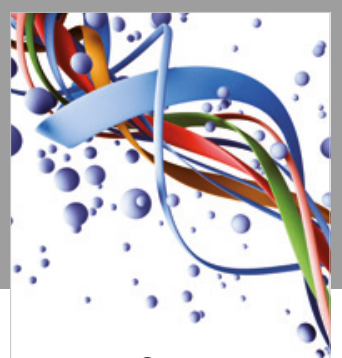

Scientifica

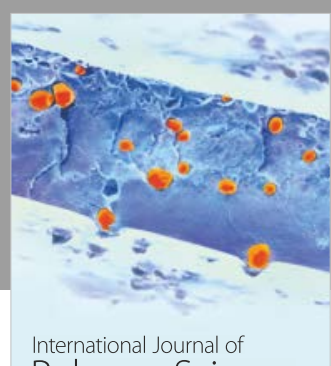

Polymer Science

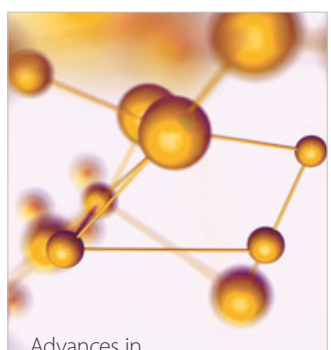

Physical Chemistry
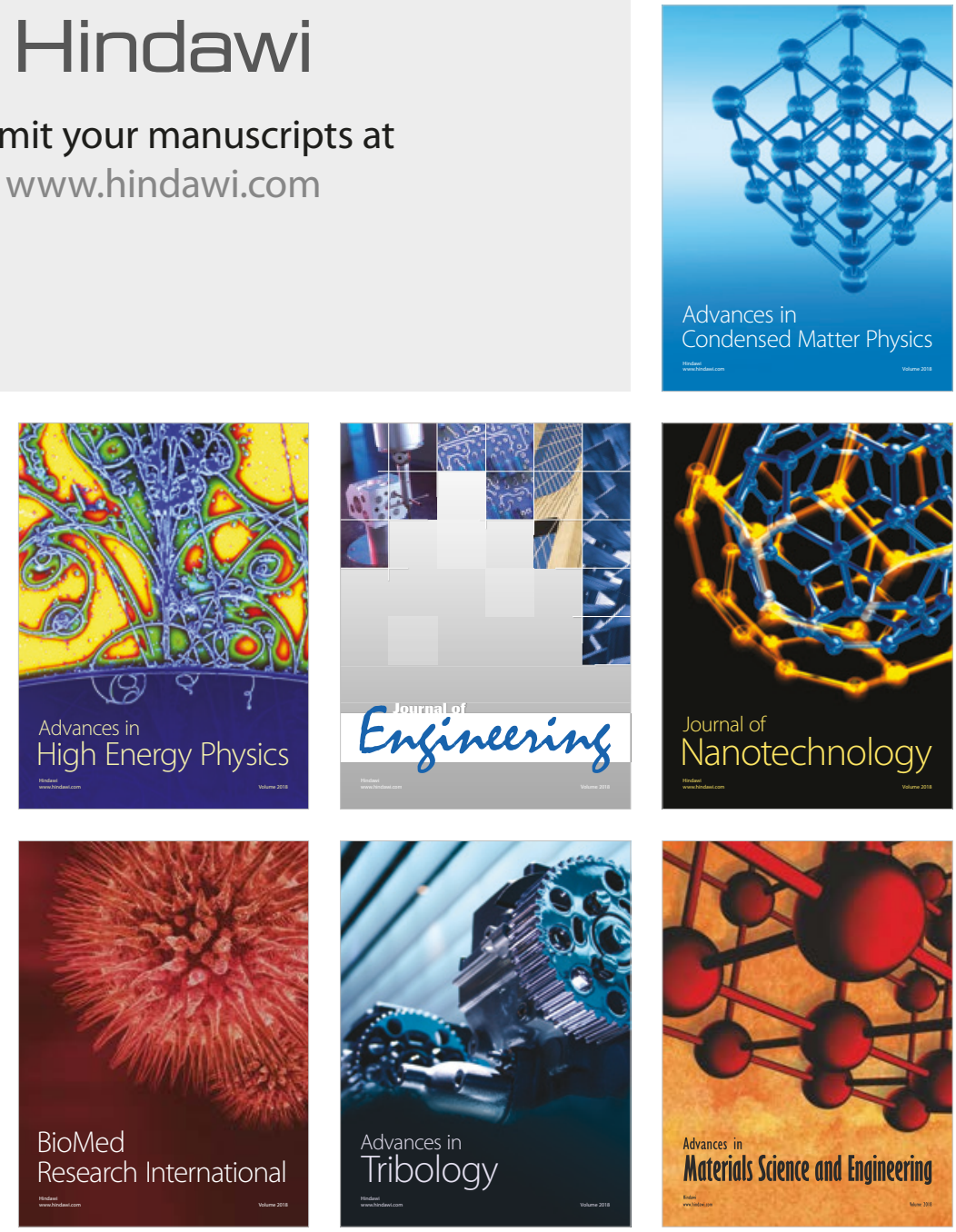